УДК 294.321; 930.85

ЖАМСУЕВА Дарима Санжиевна - кандидат исторических наук, доцент, старший научный сотрудник отдела философии, религиоведения и культурологии Института монголоведения, буддологии и тибетологии СО РАН (670047, Россия, Республика Бурятия, г. Улан-УӘэ, ул. Сахьяновой, 6; darisan@rambler.ru)

ЛУВСАН Оюунцэцэг - ученый секретарь Академии бурятоведения (Монголия, г. Улан-Батор; oyun_tb@yahoo.com)

\title{
ЦУГОЛЬСКИЙ И ШЭНЭХЭНСКИЙ ДАЦАНЫ В СРАВНИТЕЛЬНОМ АСПЕКТЕ
}

Аннотация. В статье проводится сравнительный анализ двух буддийских монастырей, один из которых (Цугольский в Забайкальском крае РФ) является исходным объектом для возведения бурятамиэмигрантами другого дацана - Шэнэхэнского в Автономном районе Внутренняя Монголия Китайской Народной Республики. Сопоставляются их архитектурные формы, внутреннее убранство, внешние составляющие этих комплексов, подчеркиваются преемственность традиции бурят и связь с материнской культурой в иноэтничной среде. При этом выявляются отдельные элементы, составляющие отличительные особенности каждого из них.

Ключевые слова: Цугольский дацан, Шэнэхэнский дацан, дацанские комплексы, архитектурные формы, внутреннее убранство, цокчен-дацан

Ц угольский дацан, расположенный на правом берегу р. Онон, в селе Цугол Могойтуйского района Агинского Бурятского округа Забайкальского края, входил в число наиболее значительных монастырей Забайкалья. Именно ему принадлежит приоритет в развитии основных направлений школ богословия - цанит и тибетской медицины - манба. К моменту фактической ликвидации в 1934 г. ${ }^{1}$ дацанский комплекс насчитывал около 20 основных и вспомогательных построек. В их числе можно отметить цокчен-дацан - главный соборный храм, цанит-дацан (чойра) - здание богословской школы, сумэ Майдари, манба-дацан - здание медицинской школы, левый и правый сумэ, посвященные сахюусанам (соответственно синему Махакале и Чойжалу), именные сумэ, относящиеся к отдельным родовым ответвлениям бурят (галзут, баруун- и зуунхаргана, баруун- и зуун-хуасай), дом Ганжирвы-гэгэна, склад ламской парадной одежды и помещения для фигур слона и лошади, которые располагались по обе стороны входных ворот (главных южных), фактически являясь их частью, здание типографии, большие молитвенные барабаны хурдэ и субурганы - монументальные культовые сооружения.

Не имея возможности в данной статье охарактеризовать весь комплекс монастыря, для наглядного представления сохранности исходных архитектурных параметров и убранства основного храма остановимся на анализе цокчендацана в Цуголе и Шэнэхэне.

Главный соборный храм Цугольского дацана - Цокчен-дацан - одна из вершин архитектурного мастерства бурятских зодчих. В бурятских летописях сохранились сведения о том, что появление в определенной местности буддийского храма было заранее предсказано. По преданию, святейшество богдо Банчен Чоглай Намжил пророчил ученому цоржи гэлуну Цультиму: «...в грядущем будущем времени буряты воздвигнут в некий период, в местности Цугол монастырь» [Летописи хоринских бурят 1940: 54].

Первые официальные сведения по строительству дацана относятся к 1826 г.,

${ }^{1}$ Агинский государственный окружной архив (АГОА). Ф. 42. Оп. 1. Д. 62. Л. 28. 
когда буряты зуун-харганатского, зуун-хуацайского и галзутского родов ввиду удаленности от приходского Агинского дацана обратились к начальнику Нерчинского округа с просьбой ходатайствовать перед вышестоящими организациями о разрешении им построить деревянную кумирню у хребта Урдунуй. Разрешение за № 111 было получено в марте 1826 г. ${ }^{1}$

В официальном списке «Ламайские дацаны Восточной Сибири» основание Цугольского дацана датируется 1801 г. [Кирилов 1896: Прил. II]. Первоначально это был войлочный храм [Ламаизм в Бурятии... 1983: 47]. Мощный импульс к дальнейшему росту Цугольский дацан получил после того, как «зайсаны ближайших окрестностей Онона, Цугола и Аги - Хуяк Лубсаев и Тугулдур Тобоев... попросили главного ламу пандита-хамбу забайкальских буддистов о присылке ламы... По приказу пожаловал шанзодба Худунского дацана Лубсан Дондоб Дандаров» [Летописи хоринских бурят 1940: 54], именуемый в летописи основателем дацана.

По той же летописи, постройка трехэтажного деревянного здания была начата в 1831 г. и завершена в 1834 г. По окончании строительства был совершен ритуал освящения, во время которого «устраивали молебствие свыше двухсот лам, собралось и молилось около 3000 человек» [Летописи хоринских бурят 1940: 31, $39,54]$. Цугольский дацан получил название Даши Чойнпиллинг. Хранителем его был определен Чойжал - одно из гневных божеств буддийского пантеона.

Цокчен-дацан представляет собой наиболее монументальную, роскошно декорированную постройку бурятских мастеров с заимствованиями из китайского и тибетского стилей. Внутреннее его убранство мы представляем фрагментарно по дневниковым записям Б. Барадина: «Храм - 3-х этажный, за исключением верхнего этажа, - весь из кирпича. Покрыт обыкновенным кровельным железом под желтую краску и подделан под вид китайской черепичной покрышки.

На обоих краях лицевой стороны нижнего этажа прибиты золоченные на меди накрест лежащие ваджры [символ крепости, несокрушимости]. На каждой стороне - расположены по 5 ваджр.

Начиная с обоих краев наружной стены [нижнего этажа] поднимаются две чугунные лестницы, ведущие во 2-й этаж. Эти лестницы были специально заказаны в Петровском Заводе. Украшены статуэтками львов, которые вставлены на обеих полосах, за которые держат руками... Лестницы находятся под открытым небом и поддерживаются на месте изгиба одним тонким чугунным столбиком. Каждая лестница имеет один изгиб, и каждая половина - по 20 ступеней.

Под отделением второго этажа, которое висит на шести колоннах, образуется открытая обширная площадь перед дверьми. Эта площадь служит крыльцом храма, и поднимается оно с юга мраморными ступенями. Пол крыльца перед каждым из трех дверей - мраморный, а остальная часть пола устлана кирпичом. На боковых сторонах крыльца обнесены невысокие кирпичные обыкновенные стенки...

Кругом на тех сторонах его сделаны деревянные перила из “бумб” в желтый цвет. Так как длина отделения меньше главного корпуса храма, то оставляет по обеим своим сторонам - на главном корпусе два свободных пространства. На этих 2-х пространствах прикреплены два “Намжу вандан'ы” [rnam bcu dbang ldan] из золоченой меди...

Существенным украшением внешности храма представляют весьма толстые карнизы, богато украшенные деревянной резьбой в несколько рядов и выкра-

${ }^{1}$ Институт восточных рукописей Российской академии наук (ИВ РАН). Ф. 44. Оп. 1. Д. 133. Л. 100. 
шенные в желтые цвета - в обыкновенном китайском стиле, как-то: тумын жаргаланы, цветы лотоса и т.д.

Все углы храма, как в китайском стиле, весьма приподняты концы углов верхнего этажа оканчиваются головами водяных чудовищ “макаров”, а концы углов среднего этажа оканчиваются волнообразными украшениями “угулзы”. На концах же нижнего этажа - нет никаких украшений...

При входе чрез главную среднюю дверь внутренность храма представляет просторную слабо освещенную залу с красными колонами и своеобразным убранством.

Южная и северная стены увешаны иконами и прочими предметами, а западная и восточная стены, как упомянуто раньше, - совершенно голы» [Дневник вольнослушателя... 2013: 118-135].

Таким образом, основываясь на записи Б. Барадина по описанию цокчендацана, мы имеем возможность фрагментарно восстановить его содержание и внутреннее пространство.

В 1935 г. на основании Постановления ЦИКа БМАССР от 20 апреля за № 28 принадлежащие Цугольскому дацану культовые предметы и атрибуты буддийской практики были переданы «члену комиссии - представителю Антирелигиозного музея системы ВКП БМАССР в лице тов. Нацова Г.Д. на основе доверенности Антирелигиозного музея от 19 октября 1935 г. за № 127... безвозмездно» 1 , а 3 октября 1936 г. представитель Агинского аймачного исполнительного комитета Дамбоин Шираб-Нимбо и представители 57-й стрелковой дивизии военный инженер Золотарев и лейтенант Пенегин на основании Постановления Президиума ЦИКа БМАССР от 8 августа 1936 г. за № 74 составили приемо-сдаточный акт о передаче строений, оставшихся в Цугольском дацане, в ведение НКО 57-й СД безвозмездно.

В 1988 г. Цугольский дацан был возвращен буддийской общине. Начался новый отсчет деятельности буддийского храма на нелегком пути возвращения к духовным истокам.

Охарактеризованный выше яркий образец бурятского зодчества второй половины XIX в. усилиями группы бурят, обосновавшихся на северо-востоке Китая, нашел свое новое воплощение. Первые переселенцы из забайкальских степей на территории Китая расположились в местности Шэнэхэн, в 30 км от г. Хайлара, в период обострения конфликта на межнациональной основе еще после революции 1905-1907 гг.2 Миграция бурят приобрела массовый характер во времена потрясений Гражданской войны в России и начавшихся преобразований в стране. Шэнэхэнские буряты - это локальная этническая группа, компактно проживающая в Хулун-Буирском аймаке Эвенкийского хошуна Внутренней Монголии Китая, предки которых в основном являлись выходцами из Приононья, Борзи, Агинских степей Забайкальского края. Таким образом, вполне логичным представляется решение выходцев из России при возведении храма на новом месте обитания обратиться к архитектурному облику традиционного объекта вероисповедания и поклонения. Построенный в 1928 г. на правом берегу р. Шэнэхэн в Эвэнкийском хошуне Хулун-Буирского аймака АРВМ КНР буддийский храм, получивший название Даша Дондоблин, являлся по архитектурному облику подобием Цугольского дацана. Во времена «культурной революции» в 1966 г. он был разрушен, а в 1984 г. отстроен и восстановлен в прежнем виде. По свидетельству местного историка С. Жамса, «прибывшие из России ламы являлись в большинстве своем монахами

${ }^{1}$ АГОА. Ф. 42. Оп. 1. Д. 39. Л. 47(об), 48.

2 Там же. Д. 62 . Л. 28. 
Цугольского, Агинского, Гунэйского дацанов [Забайкалья]. Кроме того, было несколько лам из Эгитинского, Чисанского, Зугалайского дацанов [Бурятии]. Таким образом, основной состав монахов составляли служители Цугольского дацана, а настоятелем был назначен Наянтайн Жалсан, занимавший в свое время высокую должность в том же Цугольском дацане» [Жамса 2017: 105]. Все это обусловило, по мнению исследователя истории шэнэхэнцев, преемственность традиции, которая проявилась не только при строительстве здания монастыря, соблюдении основных архитектурных форм, но и в организации монастырской деятельности, прежде всего начитывании ежедневных и крупных хуралов/молебнов, отправлении религиозных нужд, как было принято в Цугольском дацане.

При посещении восстановленного и ныне действующего Шэнэхэнского дацана было выявлено, что характерной чертой явилось стремление шэнэхэнских бурят подчинить строительство своего дацана бурятской школе буддийского зодчества, в данном случае - образцу Цугольского дацана. Это говорит о желании шэнэхэнцев сохранить свои родовые традиции, свою направленность и некоторую общность с родиной. Следует подчеркнуть, что «образцовый» Шэнэхэнский дацан отражает все многообразие архитектуры и всю сложность символики декоративных элементов, характерных для Цугольского дацана. Это и ярусное развитие объема в виде ступенчатой пирамиды с галереями и колоннадами на верхних этажах, и яркая полихромия, и крыша с поднятыми углами, и поэтажные залы с рядами колонн. Творческая самостоятельность шэнэхэнцев проявилась, на наш взгляд, только в оформлении колонн портика (в Цугольском дацане они выполнены из зеленой майолики), оформлении окон (цветовое различие в стилистике) и в некоторых незначительных декоративных элементах. Внутреннее убранство Шэнэхэнского дацана отражает также традиции Цугольского дацана (в целом - иконографический канон северного буддизма), но отличительной особенностью алтарного храмового буддийского пантеона в Шэнэхэнском дацане является новшество, традиционное для Китая, - это Будда из белого фарфора. Характерной особенностью сходства архитектурной выразительности лицевой стороны храма является ажурная чугунная лестница, стенки которой украшены решетчатыми культовыми элементами - фигурами львов-чакр. В цугольском варианте он изображен в виде закрытой орнаментальной композиции по типу «облачного узора», а в шэнэхэнском та же композиция выполнена в более грубой форме. Вероятно, шэнэхэнские буряты считали архитектуру Цугольского дацана наиболее точным воспроизведением руководящего религиозного принципа. Продолжая идти своим путем, они практически через столетие воспроизвели «свой» дацан-спутник, к приходу которого относились их родители.

Шэнэхэнские буряты, оказавшиеся изолированными от материнского этноса, выбрали, сознательно или бессознательно, замкнутый круг традиционного уклада жизни. В отрыве от основной массы этноса, в иноэтничной среде у переселенцев-бурят актуализировалась дихотомия «мы - они», выдвинувшая на первый план этноинтегрирующие признаки. Основным фактором их единения/сплочения служила религия, центром их консолидации стал Шэнэхэнский дацан. Подтверждением этому служит утверждение краеведа С-Е. Сэмжэда: «Расцвет культуры Шэнэхэна берет начало от Шэнэхэнского дацана» [Сэмжэд 2013: 8]. Она связывает благополучие и благоденствие китайских бурят с деятельностью священнослужителей, игравших на первых и дальнейших этапах обустройства на новой территории первостепенную роль. Ламы не только наставляли своих подопечных. Их роль неоценима и в отправлении нужд жизненного цикла мирян при рождении, смерти, бытовой повседневности. Кроме 
того, шэнэхэнское духовенство отличалось высокой образованностью и громадным багажом традиционных знаний, к примеру в изготовлении лекарственных средств и их применении в лечении.

Работа выполнена при поддержке РФФИ-МОКНМа в рамках научно-исследовательского проекта № 18-512-94003 «Сохранность и трансформация фольклорных и этнокультурных традиций бурят России, Монголии и Китая».

\title{
Список литературы
}

Дневник вольнослушателя Санкт-Петербургского университета Базара Барадина по бурятским дацанам (1903-1904) (подг. к публ., пред., ком., указ. Д.С. Жамсуевой). 2013. Улан-Удэ: Изд-во БНЦ СО РАН. 237 с.

Кирилов Н. 1896. Дацаны в Забайкалье. Хабаровск: Зап. Приам. Имп. РГО. T. 1. Вып. II. 133 c.

Ламаизм в Бурятии ХVIII - начала ХХ вв. 1983. Новосибирск: Наука. 247 с.

Летописи хоринских бурят: хроники Тугулдур Тобоева и Вандана Юмсунова. 1940. М.; Л.: Изд-во АН СССР. 107 с.

Жамса С. Буряад-монголшуудай Шэнэхээн нютагай түҮхэ [История бурятмонголов из Шэнэхэна]. 2017. Улаан-Удэ: Бальжинимаев А.Б. 144 с.

Сэмжэд С.-Е. 2013. Шэнэхээн соелой ундарал [Истоки культуры шэнэхэнцев]. Улан-Удэ: НоваПринт. 192 с.

ZHAMSUEVA Darima Sanzhievna, Cand.Sci. (Hist.), Senior Research Fellow, Associate Professor of the Department of Philosophy, Culture and Religion Studies, Institute for Mongolian, Buddhist and Tibetan Studies, Siberian branch of the Russian Academy of Sciences (6 Sah'janovoj St, Ulan-Ude, Republic of Buryatia, Russia, 670047; darisan@rambler.ru) LUVSAN Oyuuntsetseg, Academic Secretary of the Academy of Buryat Studies (Ulan-Bator, Mongolia; oyun_tb@ yahoo.com)

\section{TSUGOL AND SHENEKHEN DATSANS IN THE COMPARATIVE ASPECT}

\begin{abstract}
The authors make a comparative analysis of two Buddhist monasteries: Tsugol and Shenekhen. Tsugol monastery, which is situated in the Zabaykal district of the Russian Federation, is an initial object for construction of another datsan Shenekhen one - in the Inner Mongolia Autonomous Region of People's Republic of China by Buryat emigrants. The authors compare architectural forms, internal furniture and external components of these complexes and emphasize the continuity of tradition of the Buryats, their connection with maternal culture in the alien environment. At the same time, the authors reveal the separate elements making distinctive features of each monastery.
\end{abstract}

Keywords: Tsugol datsan, Shenekhen datsan, datsan complexes, architectural forms, internal furniture, Tsokchen-dugan 